\title{
Imaging of the Carotid Artery Vulnerable Plaque
}

\author{
Luca Saba $\cdot$ Michele Anzidei $\cdot$ Beatrice Cavallo Marincola $\cdot$ Mario Piga $\cdot$ \\ Eytan Raz • Pier Paolo Bassareo • Alessandro Napoli • Lorenzo Mannelli • \\ Carlo Catalano $\cdot$ Max Wintermark
}

Received: 4 June 2013/Accepted: 3 July 2013/Published online: 3 August 2013

(C) Springer Science+Business Media New York and the Cardiovascular and Interventional Radiological Society of Europe (CIRSE) 2013

\begin{abstract}
Atherosclerosis involving the carotid arteries has a high prevalence in the population worldwide. This condition is significant because accidents of the carotid artery plaque are associated with the development of cerebrovascular events. For this reason, carotid atherosclerotic disease needs to be diagnosed and those determinants that are associated to an increased risk of stroke need to be identified. The degree of stenosis typically has been considered the parameter of choice to determine the therapeutical approach, but several recently published investigations have demonstrated that the degree of luminal stenosis is only an indirect indicator of the atherosclerotic
\end{abstract}

L. Saba $(\bowtie) \cdot$ M. Piga

Department of Radiology, Azienda Ospedaliero Universitaria

(A.O.U.), di Cagliari - Polo di Monserrato, s.s. 554,

09045 Monserrato, Cagliari, Italy

e-mail: lucasaba@tiscali.it

M. Anzidei - B. C. Marincola · A. Napoli - C. Catalano Department of Radiology, Policlinico Umberto I, Sapienza University of Rome, via Regina Elena 324, 00161 Rome, Italy

E. Raz

Department of Radiology, New York University School of Medicine, New York, NY 10016, USA

P. P. Bassareo

Department of Cardiology, Azienda Ospedaliero Universitaria

(A.O.U.), di Cagliari - Polo di Monserrato, s.s. 554,

09045 Monserrato, Cagliari, Italy

L. Mannelli

Department of Radiology, University of Washington,

325 9th Avenue, Box 359728, Seattle, WA 98104, USA

M. Wintermark

Department of Radiology, Neuroradiology Division, University of Virginia, 1215 Lee Street-New Hospital, 1st Floor,

Room 1011, PO Box 800170, Charlottesville, VA 22908, USA process and that direct assessment of the plaque structure and composition may be key to predict the development of future cerebrovascular ischemic events. The concept of "vulnerable plaque" was born, referring to those plaque's parameters that concur to the instability of the plaque making it more prone to the rupture and distal embolization. The purpose of this review is to describe the imaging characteristics of "vulnerable carotid plaques."

Keywords Carotid artery - Vulnerable plaque . CTA $\cdot$ MRA $\cdot$ US-ECD

\section{Introduction}

Atherosclerosis involving the carotid arteries is a disease with a high prevalence in the population, particularly in elderly patients, and carotid artery narrowing has been reported in up to $75 \%$ of men and $62 \%$ of women aged 65 years [1]. Atherosclerotic disease of the carotid arteries is a significant condition as accidents of the carotid artery plaques have been associated with the development of cerebrovascular events [2]. For this reason, detection of carotid atherosclerotic disease and identification of those determinants that are associated to an increased risk of stroke are critical components to the prevention of stroke.

The degree of luminal stenosis typically has been considered as the most important element to grade the severity of carotid atherosclerotic disease. However, several recent investigations have demonstrated that the plaque structure and composition may represent a more direct biomarker for the development of cerebrovascular ischemic events [3-6]. From a conceptual point of view, this is easy to understand: the majority of ischemic infarcts occur because emboli originating from the heart or a carotid plaque occlude an 
arterial vessel of the brain and not because there is a reduced blood flow from a luminal stenosis, usually wellcompensated thanks to the Circle of Willis and other cerebral collateralization.

In the late 1980 s, coronary artery angiographic studies showed that coronary artery plaques causing only a moderate degree of stenosis can lead to an acute myocardial infarction $[7,8]$, confirming that luminal narrowing was not the cause of the myocardial infarction. Histopathological studies demonstrated that erosion and disruption was present in those plaques associated with myocardial infarction. Similar conclusions were reached for the carotid arteries as studies found that cerebrovascular events also can occur in patients with carotid plaques causing low-grade stenosis $(<30 \%)$ and with no other identifiable cause for their stroke [9-11].

These findings have generated tremendous interest for the development of noninvasive methods that can measure the total volume of the plaque and reliably identify the morphologic features of "vulnerable plaques" [12-14]. Another significant observation is that carotid artery plaques change over time: the composition of carotid plaques varies with the progression of atherosclerotic disease, and some phases seem to be more prone to plaque accidents and cerebrovascular events [15]. The American Heart Association (AHA) proposed a 6-stage plaque classification, which is considered to reflect the temporal natural history of the disease (Table 1).

\section{The Concept of Vulnerable Plaque and its Clinical Impact}

A number of carotid plaque features have been associated with an increase risk of stroke [16, 17], whereas others are associated with a reduced risk of ischemic events [18]. Howard et al. found that different types of plaque are associated with different types of ischemic events. Carotid plaques from patients treated with endarterectomy because of previous ocular ischemic events have fewer vulnerable plaque features than those from patients with recent cerebral ischemic events, possibly explaining some of the differences in risk of stroke between these groups [19].

Morphological characteristics of vulnerable plaques encompass a number of features, including the presence of a thin fibrous cap (FC) with a large lipid core, intraplaque hemorrhage (IPH), and the presence of intraplaque active inflammation [3, 20]. Unstable plaques also tend to be characterized by an eccentric distribution, an irregular surface without erosion of the intimal layer or superficial ulcerations with intimal exposure (Fig. 1). These features are strongly associated with significant hemodynamic changes and shear stress. The presence of plaque inflammation increases the potential vulnerability of the plaque, as chronic inflammation (histologically visible as the presence of macrophages and $\mathrm{T}$ lymphocytes) promotes vasa vasorum weakening, plaque connective-tissue rupture, and arterial wall thrombosis. Finally, the concept of remodeling, initially described for atherosclerotic lesions in coronary arteries, is now largely accepted for carotid arteries. Unstable plaques can show either positive or negative remodeling. Positive remodeling is a dilation of the vessel wall in response to an increase in the plaque/wall volume in order to maintain sufficient lumen diameter [21]. When this compensatory enlargement is inadequate to ensure a sufficient lumen size, negative remodeling with lumen stenosis occurs.

\section{Plaque Surface Morphology}

The morphology of the luminal surface of carotid plaques, classified as smooth, irregular or ulcerated (Fig. 2), is a determinant of the risk of embolic event [4, 22]. A smooth surface configuration refers to a regular luminal

Table 1 AHA classification and imaging techniques

\begin{tabular}{|c|c|c|c|c|}
\hline Stage & Definition & US & $\mathrm{CT}$ & MR \\
\hline I & $\begin{array}{l}\text { Incorporation of scattered macrophages and foam cells within the arterial wall triggered by intralesional } \\
\text { atherogenic lipoprotein }\end{array}$ & + & + & + \\
\hline II & Development of fatty streaks & ++ & ++ & ++ \\
\hline III & Extracellular fats that break up cell-cell connections in smooth muscle layers & + & ++ & ++ \\
\hline IV & $\begin{array}{l}\text { The classic atheroma that contains a fatty necrotic core. The presence of atheroma may not narrow the vascular } \\
\text { lumen since that the affected vessels can compensate for the increase in plaque volume through a widening of } \\
\text { their external circumference rather than protrusion of plaque into the vascular lumen }\end{array}$ & ++ & +++ & +++ \\
\hline V & $\begin{array}{l}\text { Stage } \mathrm{V} \text { is further classified as three different classes: Stage Va indicates those plaques having a fatty core as well } \\
\text { as a multilayered thick fibrous cap (fibroatheroma); Stage Vb lesions are largely calcified; and Stage Vc lesions } \\
\text { are predominantly fibrous }\end{array}$ & + & +++ & ++ \\
\hline VI & $\begin{array}{l}\text { "Complex" plaque: there are areas of internal haemorrhage or focal apposition thrombosis. These lesions may } \\
\text { undergo repeated cycles of rupture, thrombosis, and remodelling }\end{array}$ & + & ++ & +++ \\
\hline
\end{tabular}



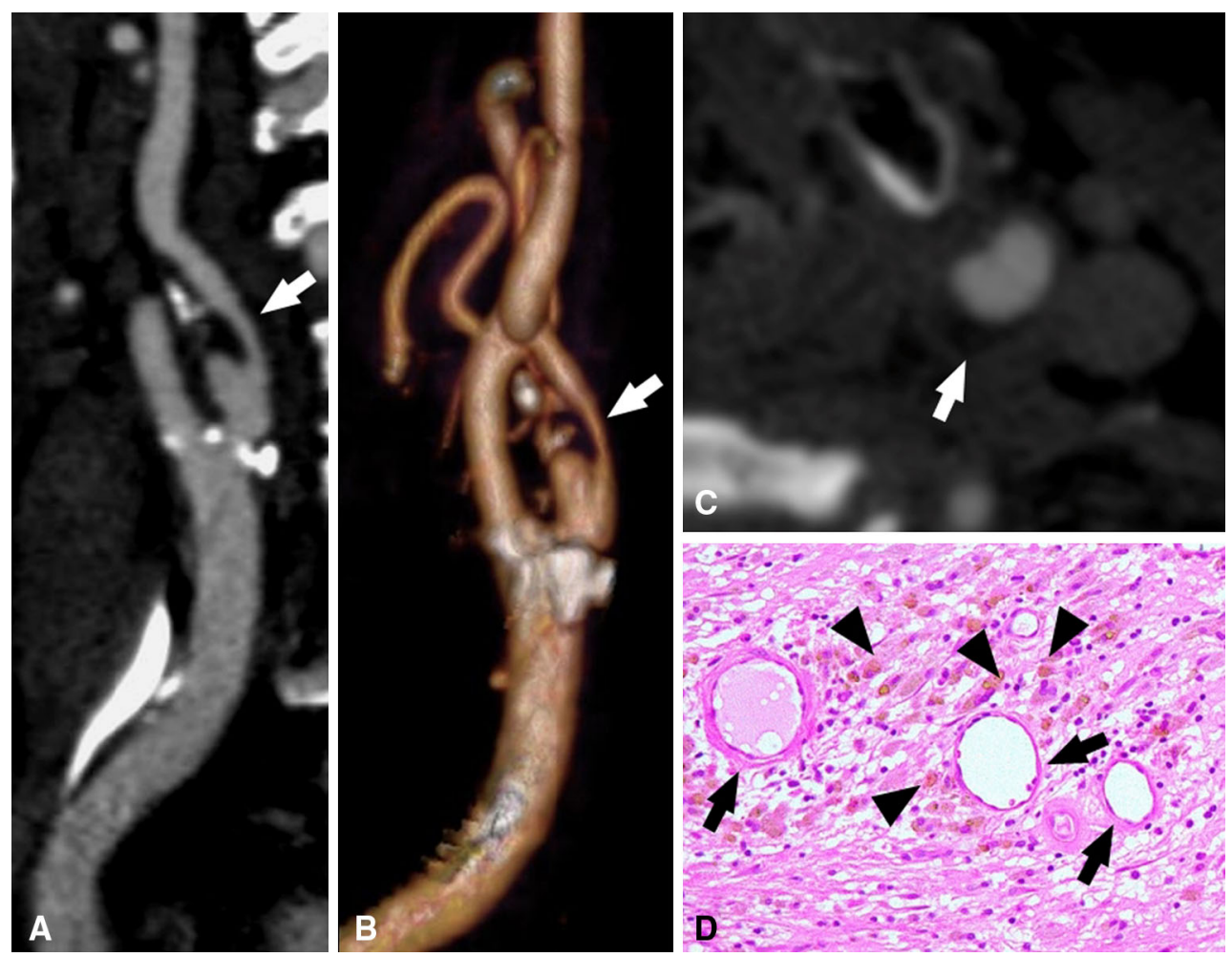

Fig. 1 Unstable plaques often are characterized by eccentric stenosis caused by a soft plaque with ulceration of the intima. a MIP reconstruction shows the presence of a wide ulcerated carotid plaque causing severe stenosis of the lumen (arrow). b Volume rendering of the same carotid plaque. CTA axial image c demonstrated a hypodense plaque (HU value 14), whereas the histological section d showed the presence of neovessels (black arrows) and macrophages (black arrowheads) morphology at the level of the plaque without any sign of ulceration or irregularity; it indicates a stable plaque. An irregular surface configuration represents a risk factor for embolism and is associated with an increased risk of TIA/ stroke [23]. The third type of morphology indicates the presence of frank ulcerations. This condition significantly increases the risk of cerebrovascular events as demonstrated in the NASCET study [24, 25]. Lovett et al. [11] suggested a classification for carotid artery ulcerations where type 1 ulcerations point out perpendicular to the lumen, type 2 ulcerations have a narrow neck and point out proximally and distally, type 3 ulcerations have a neck proximally and point out distally, whereas type 4 ulcerations have a neck distally and point out proximally.

Several studies compared different imaging techniques to assess carotid plaque ulcerations [26, 27], and the best imaging modality for this purpose is CTA [22, 28, 29]. Saba et al. [22, 28] showed in 2007 that CTA had significantly better sensitivity compared to US-ECD for the detection of plaque ulcerations (93 vs. $37.5 \%$ ). The use of post-processing techniques, especially volume-rendering algorithms, may further help in the detectionlcharacterization of carotid plaque ulcerations [28]. One of the limitations of CTA in the assessment and detection of small ulcerations is the presence of a halo or edge blur that may mask these ulcers [30, 31].

MRI can detect the presence of carotid plaque ulcerations with sensitivity similar to the CTA [32]. In a recently published paper by Etesami et al. [32], contrastenhancement MR was superior to time-of-flight (TOF) MRA for the detection of carotid ulcerations; the latter has a sensitivity of only $55 \%$, whereas contrast-enhancement MR has a sensitivity of $81.5 \%$. The false negatives on TOF MRA were related to ulcer orientation, location relative to point of maximum stenosis, and neck-to-depth ratio.

\section{The Fibrous Cap}

The FC plays a critical role in determining vulnerability of atherosclerotic plaques; particularly, the thickness and morphology are important predictors of rupture. Histologically, the FC is constituted by smooth muscle cells within a collagen-proteoglycan matrix associated with macrophages and $\mathrm{T}$ lymphocytes [33]. Inflammatory cells are also present at the interface with the underlying necrotic core [34]. According to histological findings, whereas an 

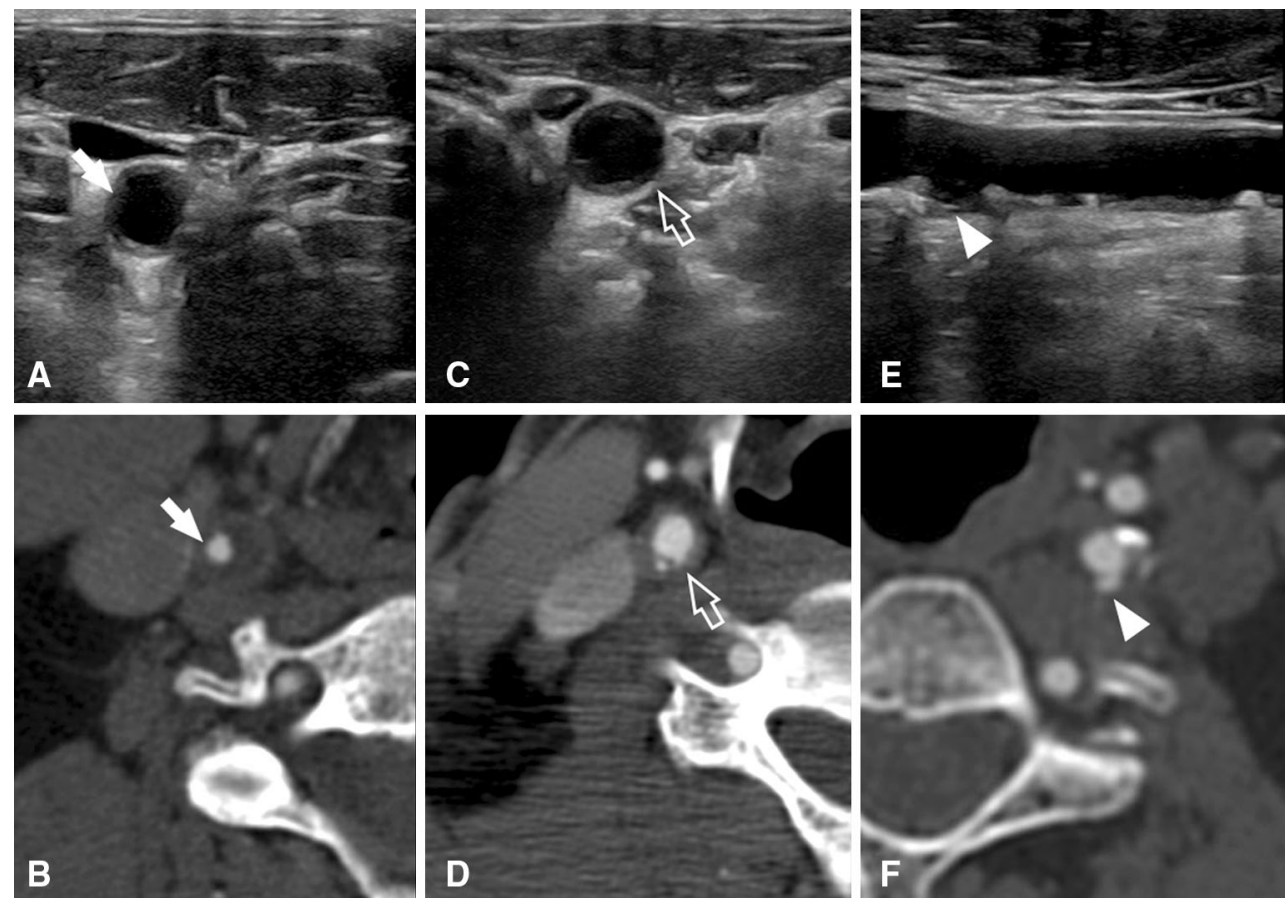

Fig. 2 Examples of different luminal morphology of the carotid artery plaques imaged using CT and US. a, b Smooth luminal surface (white arrows) for CT and US respectively. c, d Irregular luminal surface (white open arrows) for CT and US respectively. e, f Smooth plaque ulcers (white arrowheads) for CT and US respectively

masking the FC. Currently, no imaging studies have been used ultrasonography to assess the FC.

\section{Intraplaque Hemorrhage}

IPH is currently recognized as a high risk factor for plaque instability, because it contributes to plaque progression and destabilization [39, 40], causing complications by promoting vulnerability, luminal occlusion or embolic events. Several studies have found a strong association between IPH and cerebrovascular events [41-43]. Gross and microscopic pathological investigations suggested that IPH occurs more often in symptomatic patients undergoing CEA and that the age of the hematoma correlates with the timing of the symptoms [44, 45]. Histopathological examinations have revealed the association between IPH and the presence of neovessels [46]. Particularly, a study suggested the possible rupture of neovessels as cause of production and expansion of IPH [47].

The appearance of IPH on MRI depends on the hemoglobin structure and oxidative state. Different timing patterns are known for IPHs: early and acute hemorrhage contains intracellular meta-hemoglobin, whereas extracellular meta-hemoglobin is commonly found in subacute hemorrhage; finally, chronic hemorrhage is characterized by the presence of hemosiderin (Fig. 4). MR can age IPH 


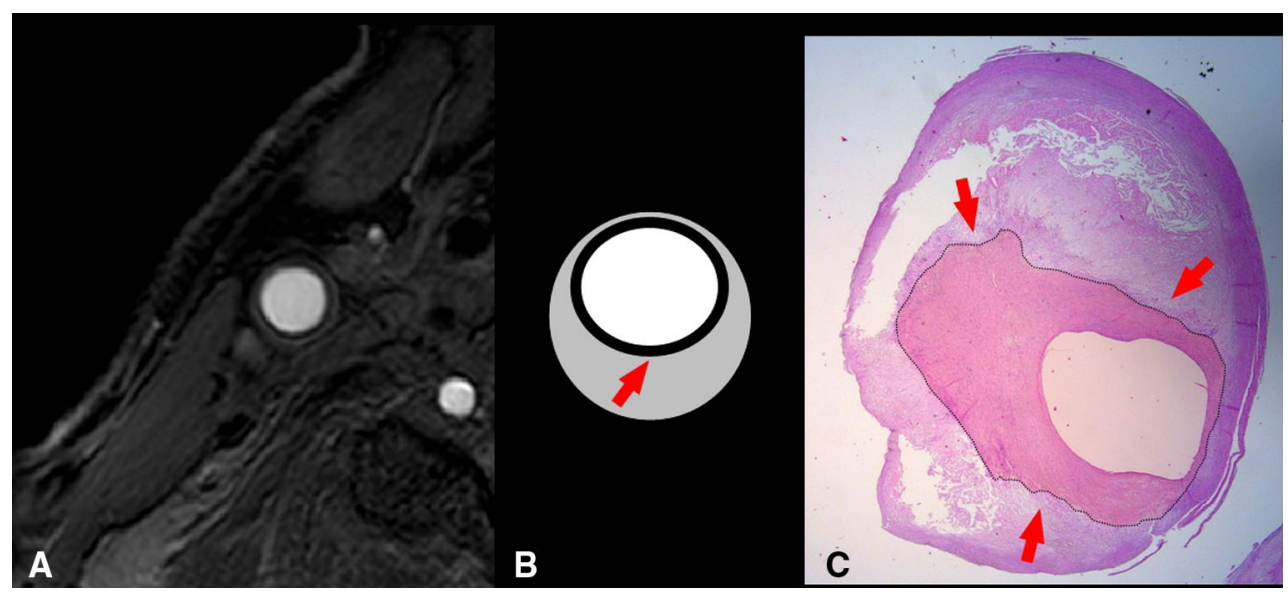

Fig. 3 a Thick fibrous caps appear as a juxtaluminal band of low signal in time-of-flight (TOF) MR images. b Schema is demonstrated (red arrow). c Histological image of a thick fibrous cap (red arrows)
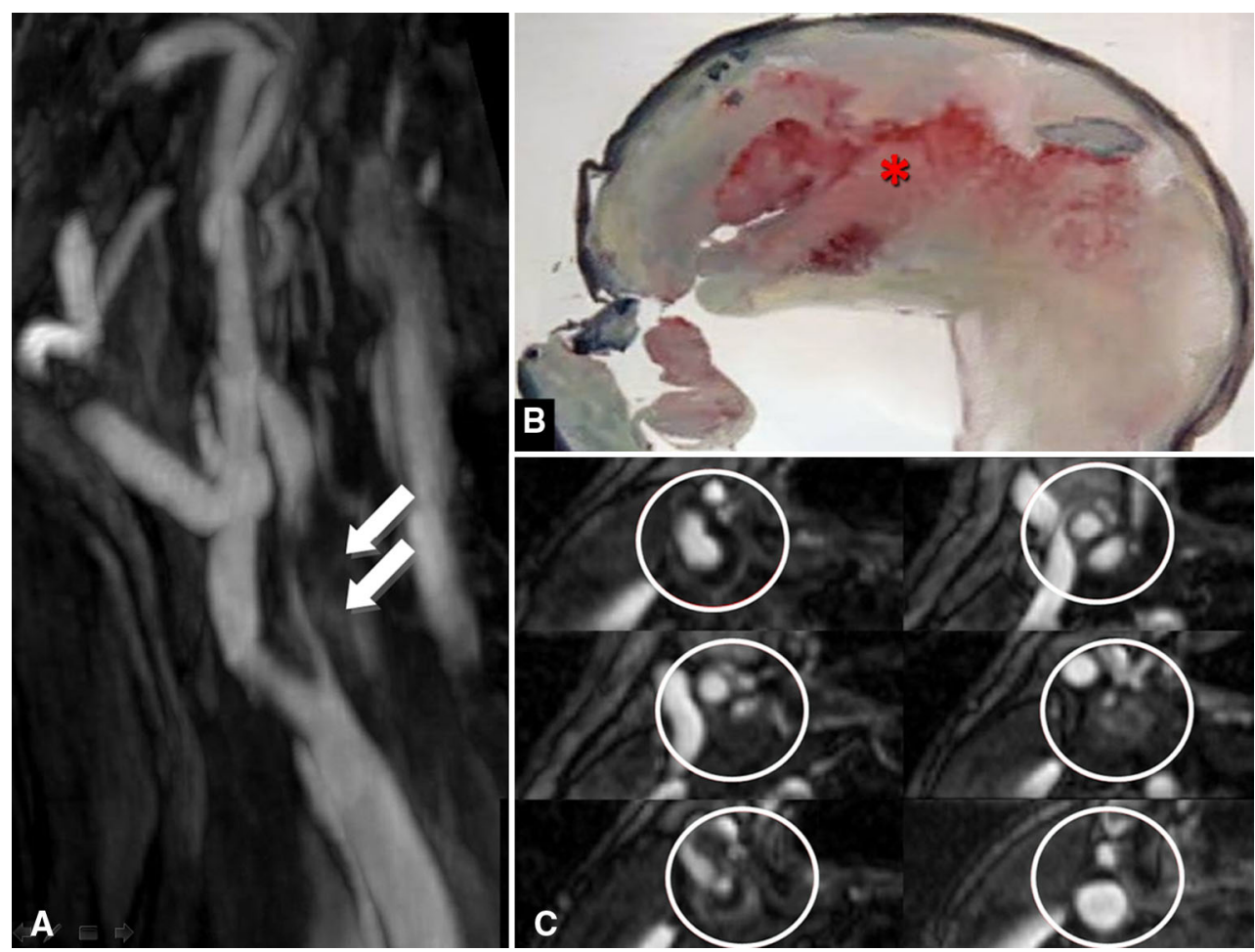

Fig. 4 High-resolution T1-weighted images acquired during the equilibrium phase of gadolinium. a The presence of a long and eccentric plaque with regular surface but enhancement of the inner plaque component (arrows), compatible with the presence of

[48-50] by distinguishing different patterns on T1-w, T2w, PD, and TOF images. Authors tried to identify IPH using $\mathrm{CT}$ and found a strong correlation between very low HU value and IPH [51, 52]. inflammation and haemorrhage. b The correspondent histological section confirmed the presence of haemorrhage within the plaque core. c Axial reformatted images show the localization of enhancement area within the plaque

\section{The Plaque Composition}

Carotid artery plaques are constituted by different components and the relative proportion of these components 
can vary greatly from one plaque to the other. These differences are important because different types of plaque are associated with different risks of stroke. Ultrasound, and especially CT and MRI, can offer information about the carotid artery plaque composition.

On CT, carotid atherosclerotic plaques are classified, according to their $\mathrm{HU}$ density, in fatty $(<60 \mathrm{HU})$, mixed $(60-130 \mathrm{HU})$, and calcified $(>130 \mathrm{HU})$ plaques [53] (Fig. 5). Very low HU value in the plaque $(<0 \mathrm{HU})$ are associated with the presence of intraplaque haemorrhage $[53,54]$. The presence of fatty plaques are associated with an increase risk of stroke [55], whereas the presence of calcium in the carotid artery plaques seems to be a protective factor $[18,56]$, which is unlike the coronary arteries $[57,58]$. It is hypothesized that calcium in the carotid atheromatous plaques confers stability, resulting in a protection against the biomechanical stress and the disruption. The presence and the amount of calcium in the carotid artery plaque can be assessed using different imaging techniques but the most sensitive technique is CT because of the high attenuation of X-rays by calcium hydroxyapatite, which leads to a high density structure in the plaque. For the CT analysis of calcified plaques, it is extremely important to correctly select the window of visualization (level and center) [59].

On ultrasonography, the analysis of the echogenicity is the main parameter that reflects the plaque composition. One of the most used method is the Gray-Weale's classification modified by Geroulakos [60] that classifies the plaque in five types according to the level of echogenicity: type 1 (anechogenic with echogenic FC); type 2 (predominantly anechogenic but with echogenic areas representing less than $25 \%$ of the plaque); type 3 (predominantly hyperechogenic but with anechogenic areas representing less than $25 \%$ of the plaque); type 4 (echogenic and homogeneous plaque); and type 5 (unclassified plaques reflecting calcified plaques with areas of acoustic shadowing which hide the deeper part of the arterial layers). It was demonstrated that types 1 and 2 are similar to CT fatty plaques, types 3 and 4 as mixed plaques, and type 5 as calcified plaques [61, 62] (Fig. 5).

MRI can depict carotid artery plaque composition but, as described in the previous section, its best potential lies in its ability to identify the presence of haemorrhage within a plaque and to characterize its age [40]. The type of the plaque is associated not only with the potential
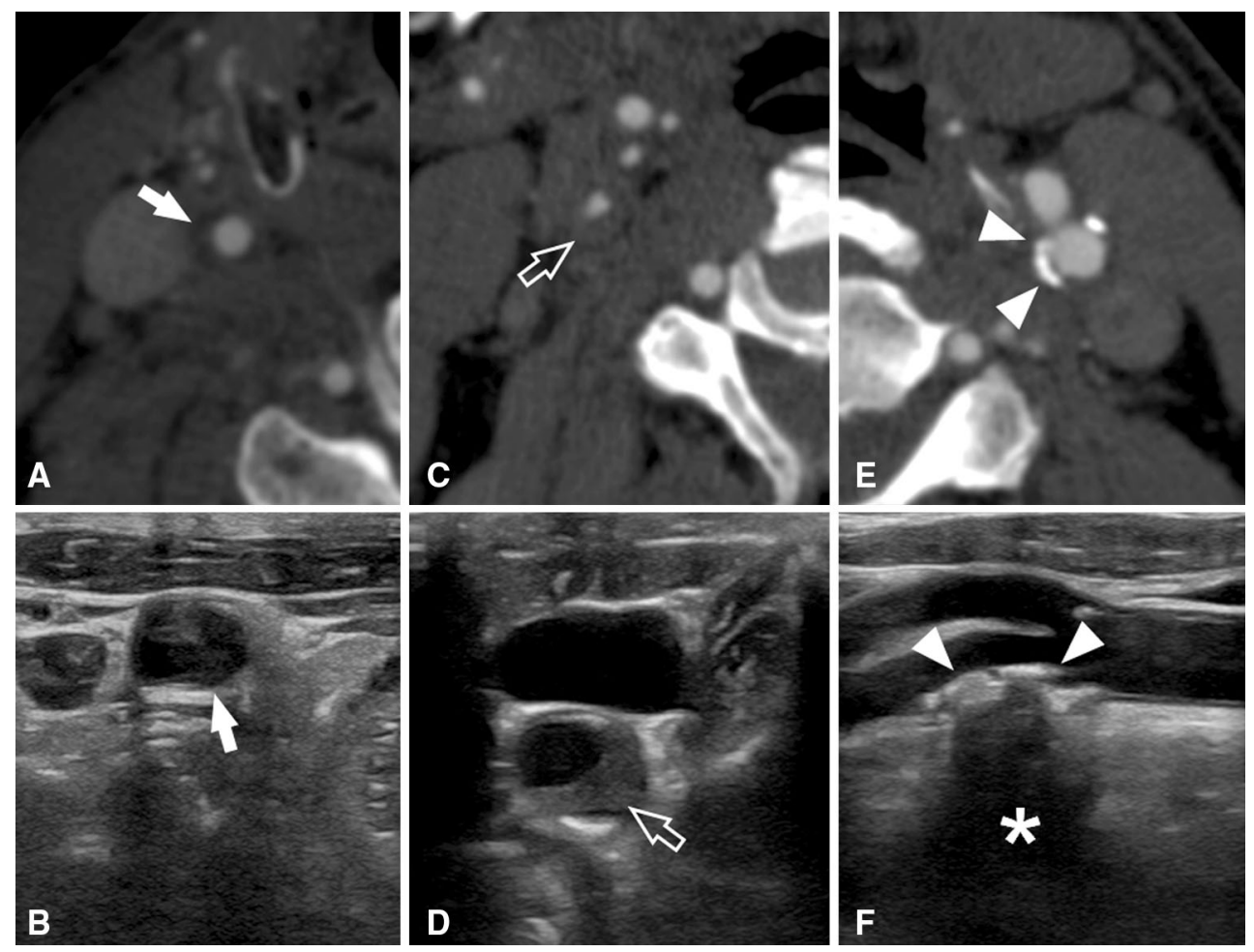

Fig. 5 Different plaque types of the carotid artery plaques imaged using CT and US. a, b Fatty plaques (white arrows) on CT corresponding to the Geroulakos class 1 on US. c, d Mixed plaques (white open arrows) on CT corresponding to the Geroulakos class 3 on US. e, f Calcified plaques (white arrowheads) on CT corresponding to the Geroulakos class 5 on US 
development of cerebrovascular events but also with the presence of other conditions that affect the brain such as cerebral micro-bleeds and leukoaraiosis [63-65].

This information also is extremely important for risk assessment of carotid artery stenting (CAS) because some conditions (circumferential calcification or large necrotic cores with thin or ruptured FC) are considered as a counterindication to the CAS procedure. In particular, Kamenskiy et al. [66] recently found that patients with circumferential, heavily calcified plaques, located in the distal portion of the internal carotid artery are most likely to have poststenting geometric changes and complications, whereas Tsutsumi et al. [67] found that in those calcified plaques that were treated with CAS there were multiple fragmentations of the calcifications (assessed by MDCT) in $94.4 \%$ of the cases.

\section{The Plaque Volume}

Recent studies have demonstrated that the volume of the carotid artery plaque, driven by the remodeling that occurs in the time, is a critical determinant of the plaque "vulnerability" and risk of rupture. Some authors have hypothesized that the plaque volume may be a better descriptor of the severity of atherosclerotic disease than the degree of stenosis it causes [68]. Noninvasive in vivo assessment of atherosclerotic plaque volume and the relative contribution of the different plaque components have important clinical implications, in terms of ischemic event risk assessment. Nowadays, dedicated CTA-based software can calculate the volume of the carotid artery plaque and determine the volume of the subcomponents. These software are based on the HU threshold, so that the operator can select for which HU a plaque can be considered fatty, mixed, or calcified. A new study published in 2013 addressed this type of quantification using MRI, but the results were less convincing because of the lower spatial resolution of MRI compared to CT [69] (Fig. 6).

The lipid component volume appears to be associated with the presence of plaque ulcerations, which represent a significant risk factor for the development of cerebrovascular events [70]. The plaque composition changes with increasing plaque volume. More specifically, there is an increase in the proportion of lipid and calcification with increasing plaque volume.

\section{The Plaque Neovascularization}

Several histopathological studies revealed that the ectopic neovascularization in the intima and media is a hallmark of advanced atherosclerotic lesions [71]. The presence of neovascularization in carotid artery plaques is considered as an element of vulnerability because these microvessels are prone to rupture, and IPH has been shown to accelerate plaque evolution [72].

Carotid contrast-enhanced ultrasonography (CEUS) can offer some information about the presence of neovascularization [73] in particular when microbubbles are used $[74,75]$. However, the reproducibility and utility of this modality for clinical care are not well established [76]. On $\mathrm{CT}$, the identification of plaque neovascularization is based on few studies [77-81] that demonstrated the ability of CT
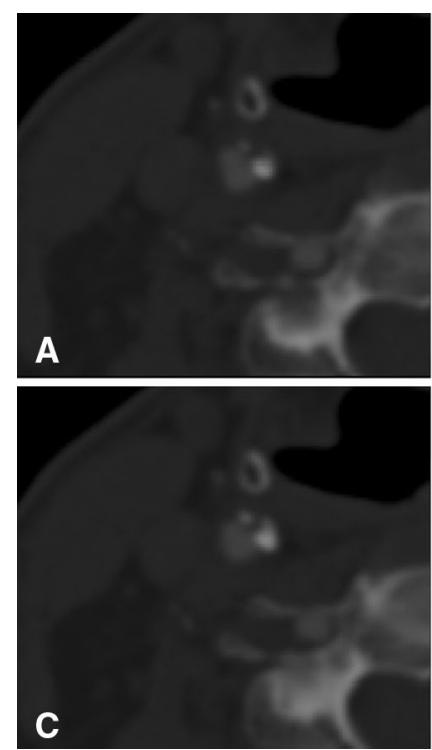
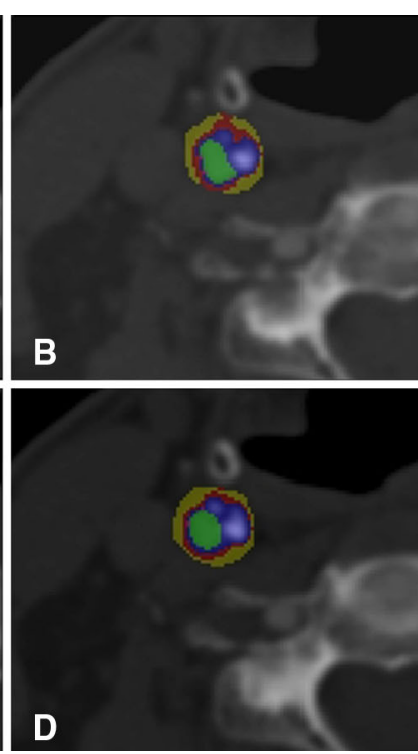
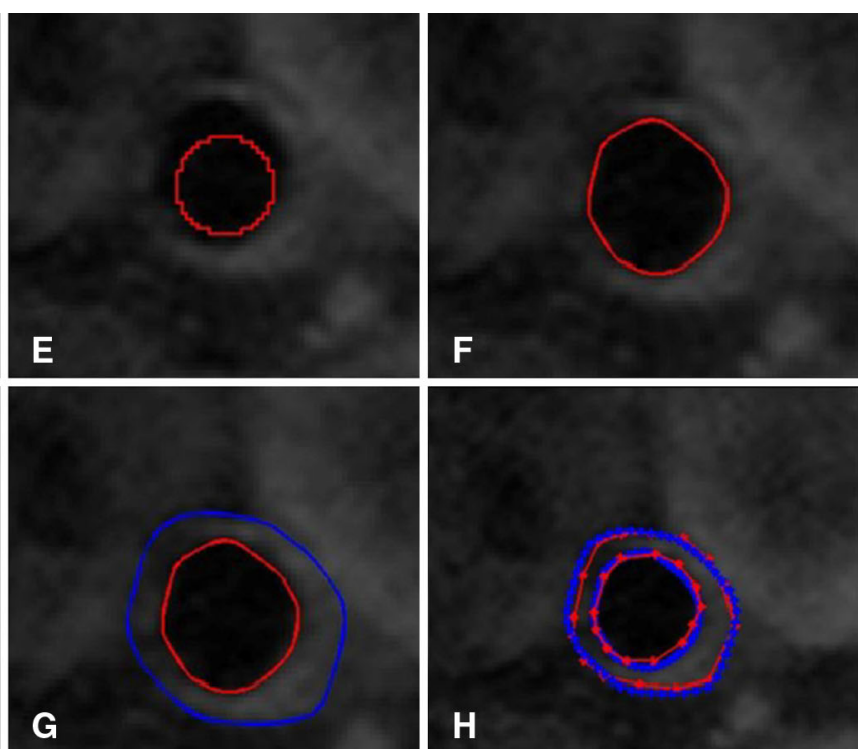

Fig. 6 Carotid CTA axial images $(\mathbf{a}, \mathbf{b})$ with automated carotid artery plaque segmentation $(\mathbf{c}, \mathbf{d})$. MR axial images $(\mathbf{e}, \mathbf{f})$ with automated carotid artery lumen detection $(\mathbf{g}, \mathbf{h})$ 


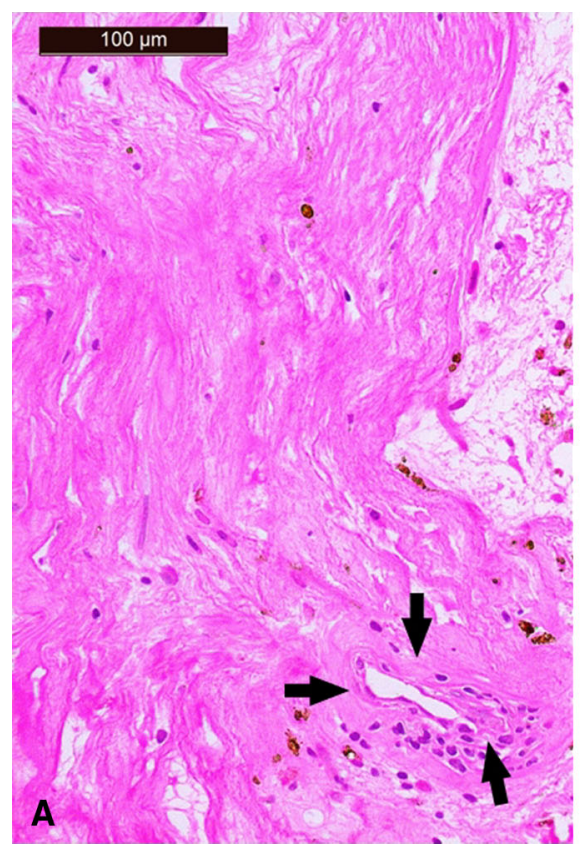

Fig. 7 Carotid contrast plaque enhancement. a Histological slice of a 67-year-old patient who underwent carotid endarterectomy where neovessels are visible (black arrows). b CT axial image of the same

to detect contrast plaque enhancement (CPE) related to the degree of neovascularization (Fig. 7).

MRI also can assess the presence of neovasculature in carotid artery plaques [82-85]. A recent study by Gaens et al. [85] showed that dynamic contrast-enhanced MR of carotid atherosclerotic plaques can assess plaque neovasculature and that the Patlak model is well-suited for describing carotid plaque enhancement; the authors found that the $\mathrm{K}$ (trans) is an indicator of plaque microvasculature (validated by histology) and that the reproducibility of $\mathrm{K}$ (trans) was good.

\section{Contrast Enhancement (US-MRI-CT)}

\section{Contrast-Enhanced Ultrasound}

CEUS represents a simple and noninvasive technique for the evaluation of plaque vascularization, allowing for the detection of plaque vasa vasorum that are abundant in vulnerable plaques [86-88].

Different ultrasound contrast agents are commercially available. They differ basing on their composition (protein, lipid, phospholipid, or sulfur hexafluoride microbubbles), but they have the common characteristic that they resonate when exposed to an ultrasound wave. The enhancement of the arterial lumen allows to assess the degree of stenosis and to evaluate luminal irregularities, dissections, or ulcerations. At the same time, the technique allows direct

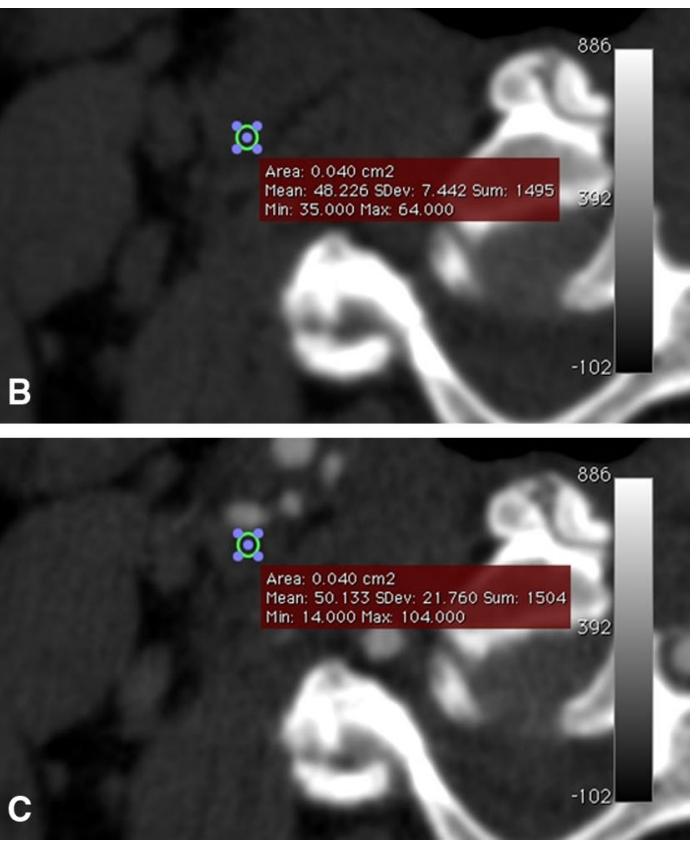

patient is given and in the plaque there is an HU value of 48. c Same section as (b) obtained after administration of contrast material: the plaque $\mathrm{HU}$ values are higher

visualization of the adventitial vasa vasorum and intraplaque angiogenesis. A recent article by Staub et al. [89] concluded that vulnerable plaques frequently have a greater degree of neovascularization and that the presence of plaque neovessels correlates with lesion severity and with morphologic features of plaque instability. Therefore, contrast-enhanced ultrasound can represent a valuable tool for risk stratification of unstable plaques [89].

High-Resolution and Contrast-Enhanced Magnetic Resonance Imaging

High-resolution magnetic resonance imaging is a useful noninvasive tool for characterizing atherosclerotic plaque composition and provides excellent images of the arterial wall. The high field strength (1.5-3 T), the high-contrast resolution and the use of dedicated surface radiofrequency coils that increase the signal-to-noise ratio allow to go beyond the assessment of stenosis degree and to depict plaque components (FC, lipidic core, calcification, IPH), Contrast-enhanced magnetic resonance angiography (CEMRA) has been demonstrated to be a very accurate noninvasive test for the detection of significant (70-99 \%) symptomatic carotid artery stenosis [90]. Different contrast agents are currently used to characterize carotid plaque. Gadolinium-chelates contrast agents are most commonly used for MRA examinations; for the assessment of unstable plaques, the vascular enhancement of the carotid plaques themselves has been demonstrated to hallmark the presence 
of an increased endothelial permeability due to plaque inflammation that facilitates the entry of contrast agents [83, 91-95].

A study by Kerwin et al. confirmed the usefulness of contrast-enhanced MR imaging in both the depiction of plaque inflammation and the differentiation of the plaque components such as fibrous or necrotic portions. Moreover, they showed that early plaque enhancement is due to the presence of internal neovessels, while late enhancement is related neovasculature supply and endothelial permeability [94]. The correlation between the degree of plaque enhancement and the degree of neovascularization, which is itself linked to the degree of plaque inflammation, also was confirmed at histology in a recent study by Millon et al. [96].

Blood-pool contrast agents (characterized by a long intravascular circulation times) and contrast agents that are characterized by an increased R1 relaxivity allow for "steady-state," T1-weighted images with increased spatial (isotropic) resolution, during the equilibrium phase of contrast circulation after the initial first pass [97]. The use of the steady state sequences combined with the first-pass study can provide additional diagnostic information comparable to that obtained with CT angiography [98] (Fig. 8).

Finally, small particles-based contrast agents (iron oxide) can be used to evaluate the presence of plaque inflammation because of their ability to enter atherosclerotic plaques with an increased endothelial permeability and accumulate in migrated macrophages [99]. High-risk inflamed plaques may be identified with a focal area of signal loss visualized on MR images, due to contrast accumulation [100]. Moreover, ultrasmall superparamagnetic iron oxide (USPIO)-enhanced MR imaging has been experimentally used as a biomarker for the screening and the assessment of therapeutic response to statins treatment.

\section{Computed Tomography Angiography}

The widespread availability of multi-detector-row CT scanners has made CT angiography the most used noninvasive technique to assess carotid arteries after color-
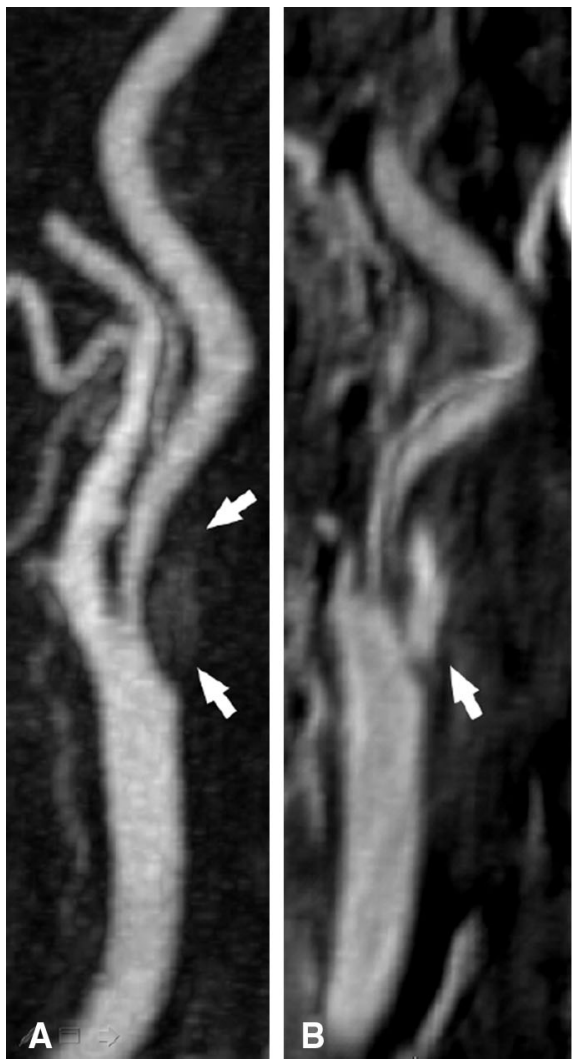

Fig. 8 CE-MRA of a vulnerable carotid plaque performed after injection of a high-relaxivity contrast agent. The use of highresolution, T1-weighted sequences acquired after the first-pass study, during the equilibrium phase, can provide additional diagnostic information, such as the presence of signs of plaque vulnerability (inflammation or haemorrhage). During the first pass of the contrast agent (a), a soft and regular plaque is depicted at the carotid

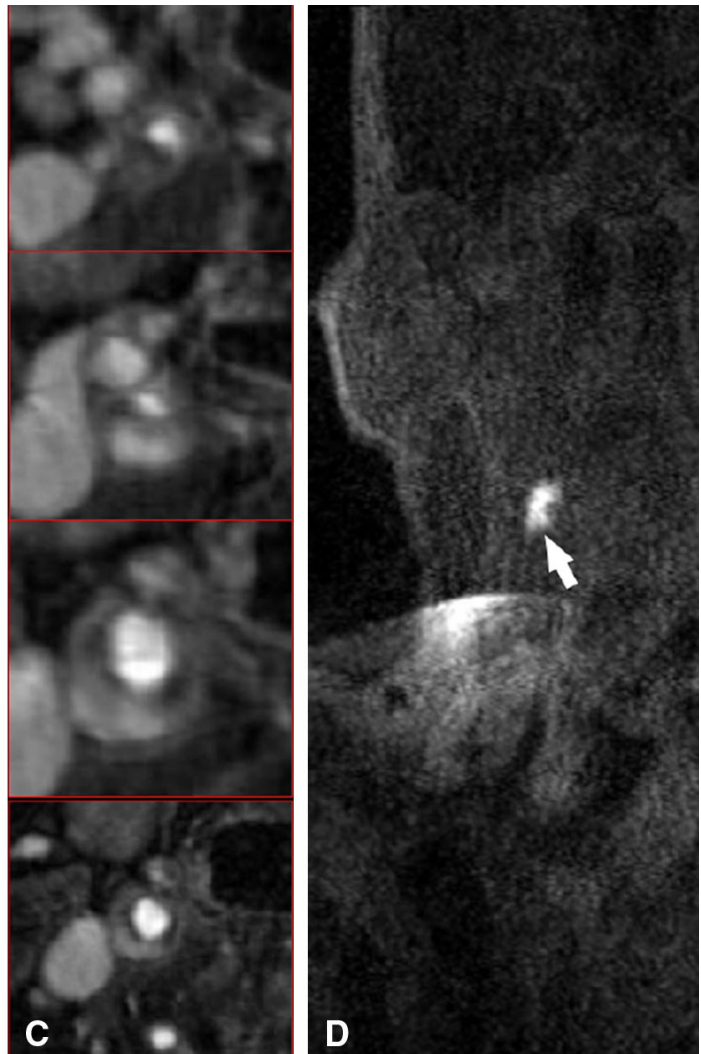

bifurcation (arrows). High-resolution, T1-weighted sequences (b) show the presence of an enhancing area within the plaque (arrow) corresponding to intraplaque haemorrhage. Axial reconstruction (c) shows the location of the enhancing area and the stenosis degree. A hyperintense area corresponding to the intraplaque haemorrhage was also visible on precontrast T1-weighted images (arrow in d) 
duplex ultrasound. The advantages of this technique are several: velocity of execution, large Z-axis coverage, possibility to use several postprocessing techniques, and the high confidence of the clinicians and surgeons with the CT images. The high spatial resolution combined with very short acquisition times make computed tomography angiography (CTA) of the carotid arteries a very useful tool for the assessment of carotid plaque burden.

A meta-analysis conducted by Koelemay et al. reported sensitivity and specificity values for CTA of 97 and $99 \%$, respectively, in terms of characterizing the degree of carotid stenosis. In particular, CTA was accurate to characterize 70-99\% stenoses and for the diagnosis or exclusion of occlusions [101]. The ability to scan with very thin slices allows for the accurate evaluation of carotid plaques and of possible intimal irregularities or ulcerations. In terms of CT characterization of plaque components, the presence of high-calcified plaques can hamper a correct estimation of the other components (lipidic core and initial signs of inflammation) because of the blurring artifacts. This limit does not exist for soft plaques.

Finally, CTA is particularly useful for the evaluation of carotid artery remodeling (modifications of lumen diameters following the development of a wall plaque) [102]. The main disadvantage of CTA is the radiation dose delivered to the patient. It is important to underline that the radiation dose can significantly change according to the type of the CT scanner used. In particular, there is a difference between the use of the single source CT versus the dual source CT technology. In a recently published paper [103], the CDTI of single source CT was $12.5 \mathrm{mGy}$, whereas using dual energy CT system was $10.64 \mathrm{mGy}$.

\section{Dual-Energy Imaging}

Recently, a new type of CT scanner was introduced: dualenergy CT. This technology allows to obtain the attenuation value of a tissue at multiple energy levels and to postprocess the dataset to evaluate the tissue attenuation determined for specific keV values [104] (Fig. 9).

Mannelli et al. [105], in a recently published "ex vivo" study, compared the size of the calcifications in the carotid artery plaques measured on the different $\mathrm{keV}$ images to a histological standard and found that calcium area measured on the $80 \mathrm{keV}$ image set was most comparable to the amount of calcium measured on histology. Saba et al. [106] assessed "in vivo" the effect of the multispectral imaging in terms of carotid artery plaque classification and found that the $\mathrm{HU}$ values of carotid artery plaque significantly change according to the selected $\mathrm{keV}$. Results from this study demonstrated that the HU-based plaque type (fatty and mixed) classification can be improved with the use of multienergy imaging.
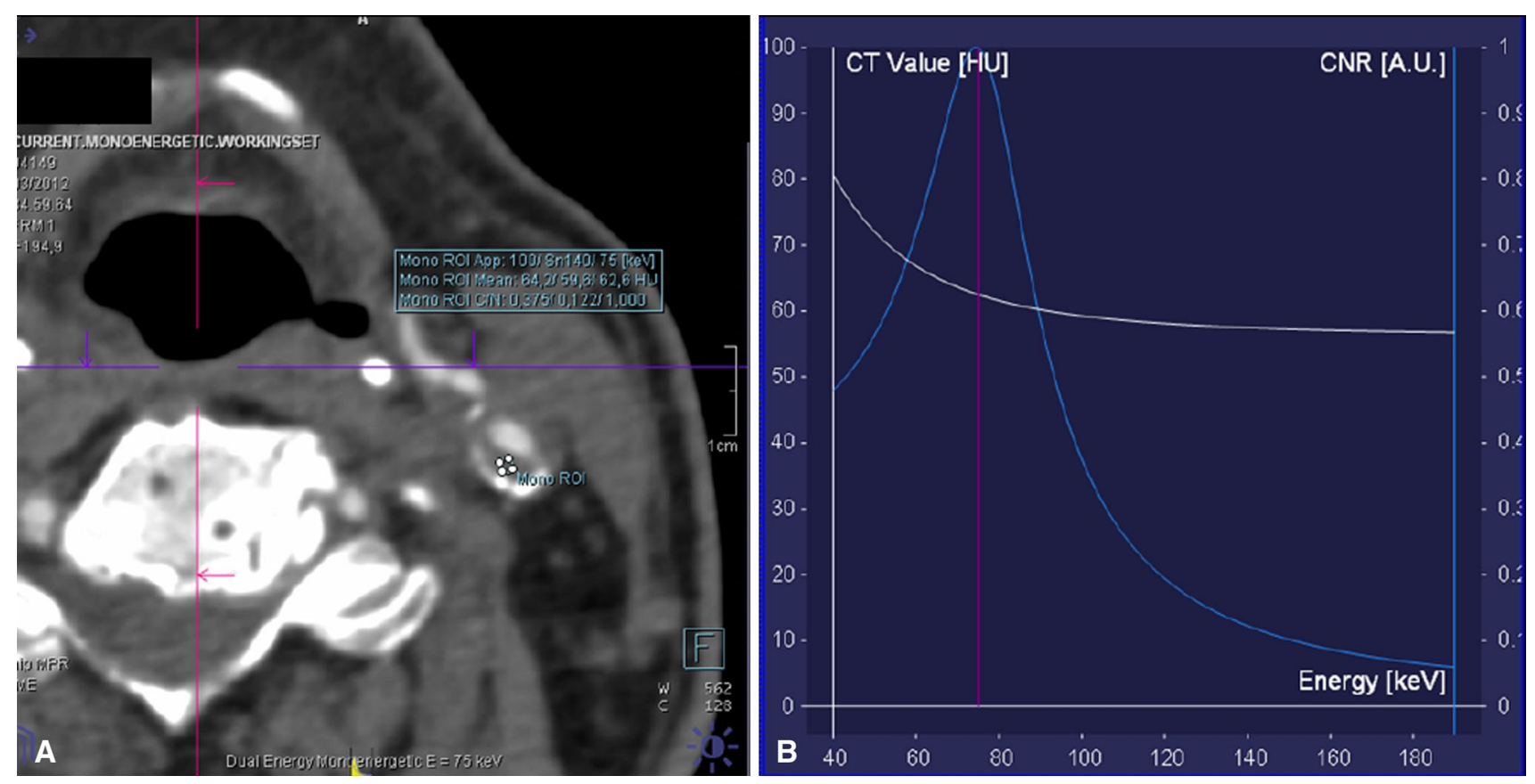

Fig. 9 The effect of the different keV levels is visible. The CTA axial image of a 62-year-old patient with a mixed plaque (a) and the variation of the $\mathrm{HU}$ value due to the variation of the $\mathrm{keV}$ is clearly visible (b) 


\section{Clinical Practice and Results from the Scientific Studies}

In the past years, several studies have demonstrated that the degree of luminal stenosis represents only one of the parameter that can determine the ischemic stroke and gradually we have evolved to the concept of vulnerable plaque from the concept of risk arising from the degree of stenosis $[9,10,107]$. However, currently there is a discrepancy between these scientific studies and clinical practice; despite of many publications and discussions, plaque imaging techniques are not really the basics of clinical decision making or current guidelines and in the majority of cases decision towards revascularization are not based on plaque morphology but on the degree of stenosis [108-110]. Evaluation of the role of predictive effects of the previously described imaging parameters are needed and further studies are necessary to incorporate the potential of the advanced imaging techniques in the identification of the vulnerable plaque to selection of the therapeutical approach. Only in this way the identification of the features of plaque vulnerability will have a bigger clinical impact. Another important issue is the economic impact of the application of CTA or MRA in the diagnostic flowcharts. Previous study demonstrated that the cost of digital subtraction angiography is very high and it can be replaced by CTA or MRA [111]; however, there is no consensus when these techniques should be used and more data are required to define the economic impact of these techniques [112].

\section{Conclusions}

Nowadays, imaging can identify and characterize determinants of carotid atherosclerotic plaque vulnerability and stratify the risk of stroke for patients affected by atherosclerotic disease of carotid arteries. Ultrasound imaging can offer valuable information about the general composition of the plaque and also about the presence and degree of neovascularization within the plaques, when combined with the use of microbubble contrast agents. CT imaging allows assessment of several characteristics of the vulnerable plaques: total volume (and the volume of the subcomponents), classification of the plaque types (fatty, mixed, calcified), analysis of the neovascularization. MRI offers the best level of assessment of carotid artery plaques by analysing features, such as the status of the FC and the presence of IPH. The use of specific contrast agents can target specific cell population, such as macrophages, which are a marker of the inflammatory process within vulnerable plaques. Further studies are necessary to incorporate the potential of the advanced imaging techniques in the identification of the vulnerable plaque to selection of the therapeutical approach.
Conflict of interest The authors declare that they have no conflict of interest.

\section{References}

1. Li R, Duncan BB, Metcalf PA, Crouse JR 3rd, Sharrett AR, Tyroler HA, Barnes R, Heiss G (1994) B-mode-detected carotid artery plaque in a general population. Atherosclerosis Risk in Communities (ARIC) study investigators. Stroke 25(12): 2377-2383

2. Salem MK, Sayers RD, Bown MJ, West K, Moore D, Robinson TG, Naylor AR (2013) Features of unstable carotid plaque during and after the hyperacute period following TIA/stroke. Eur J Vasc Endovasc Surg 45(2):114-120

3. Naghavi M, Libby P, Falk E et al (2003) From vulnerable plaque to vulnerable patient: a call for new definitions and risk assessment strategies: part I. Circulation 108:1664-1672

4. Saba L, Anzidei M, Sanfilippo R, Montisci R, Lucatelli P, Catalano C, Passariello R, Mallarini G (2012) Imaging of the carotid artery. Atherosclerosis 220(2):294-309

5. Schwarz F, Bayer-Karpinska A, Poppert H, Buchholz M, Cyran C, Grimm J, Helck A, Nikolaou K, Opherk C, Dichgans M, Saam T (2013) Serial carotid MRI identifies rupture of a vulnerable plaque resulting in amaurosis fugax. Neurology 80(12):1171-1172

6. Saba L, Sanfilippo R, Sannia S, Anzidei M, Montisci R, Mallarini G, Suri JS (2012) Association between carotid artery plaque volume, composition, and ulceration: a retrospective assessment with MDCT. AJR Am J Roentgenol 199(1):151-156

7. Ambrose JA, Tannenbaum MA, Alexopoulos D (1988) Angiographic progression of coronary artery disease and the development of myocardial infarction. J Am Coll Cardiol 12:56-62

8. Libby $\mathrm{P}$ (1998) The interface of atherosclerosis and thrombosis: basic mechanisms. Vasc Med 3:225-229

9. Lovett JK, Gallagher PJ, Rothwell PM (2004) Reproducibility of histological assessment of carotid plaque: implications for studies of carotid imaging. Cerebrovasc Dis 18:117-123

10. Wasserman BA, Wityk RJ, Trout HH, Virmani R (2005) Looking beyond the lumen with MRI. Stroke 36:2504-2513

11. Lovett JK, Gallagher PJ, Hands LJ, Walton J, Rothwell PM (2004) Histological correlates of carotid plaque surface morphology on lumen contrast imaging. Circulation 110:2190-2197

12. Kullo IJ, Edwards WD, Schwartz RS (1998) Vulnerable plaque: pathobiology and clinical implications. Ann Intern Med 129:1050-1060

13. Budinger T, Berson A, McVeigh E et al (1999) Magnetic resonance imaging of the cardiovascular system. J Cardiovasc Magn Res 1:53-58

14. Falk E, Fernandez-Ortiz A (1995) Role of thrombosis in atherosclerosis and its complications. Am J Cardiol 75:3B-11B

15. van Gils MJ, Vukadinovic D, van Dijk AC, Dippel DW, Niessen WJ, van der Lugt A (2012) Carotid atherosclerotic plaque progression and change in plaque composition over time: a 5-year follow-up study using serial CT angiography. AJNR Am J Neuroradiol 33(7):1267-12673

16. Yoshida K, Sadamasa N, Narumi O, Chin M, Yamagata S, Miyamoto S (2012) Symptomatic low-grade carotid stenosis with intraplaque hemorrhage and expansive arterial remodeling is associated with a high relapse rate refractory to medical treatment. Neurosurgery 70(5):1143-1150

17. Mauriello A, Servadei F, Sangiorgi G, Anemona L, Giacobbi E, Liotti D, Spagnoli LG (2011) Asymptomatic carotid plaque rupture with unexpected thrombosis over a non-canonical vulnerable lesion. Atherosclerosis 218(2):356-362 
18. Nandalur KR, Hardie AD, Raghavan P, Schipper MJ, Baskurt E, Kramer CM (2007) Composition of the stable carotid plaque. Insights from a multidetector computed tomography study of plaque volume. Stroke 38:935-940

19. Howard DP, van Lammeren GW, Redgrave JN, Moll FL, de Vries JP, de Kleijn DP, de Borst GJ, Pasterkamp G, Rothwell PM (2013) Histological features of carotid plaque in patients with ocular ischemia versus cerebral events. Stroke 44(3):734-739

20. Saba L, Potters F, van der Lugt A, Mallarini G (2010) Imaging of the fibrous cap in atherosclerotic carotid plaque. Cardiovasc Intervent Radiol 33(4):681-689

21. Virmani R, Burke AP, Kolodgie FD, Farb A (2003) Pathology of the thin-cap fibroatheroma: a type of vulnerable plaque. J Interv Cardiol 16(3):267-272

22. Saba L, Caddeo G, Sanfilippo R, Montisci R, Mallarini G (2007) $\mathrm{CT}$ and ultrasound in the study of ulcerated carotid plaque compared with surgical results: potentialities and advantages of multidetector row CT angiography. AJNR Am J Neuroradiol 28(6):1061-1066

23. Wasserman BA, Smith WI, Trout HH III, Cannon RO 3rd, Balaban RS, Arai AE (2002) Carotid artery atherosclerosis: in vivo morphologic characterization with gadolinium enhanced doubleoblique MR imaging-initial results. Radiology 223:566-573

24. Eliasziw M, Streifler JY, Fox AJ (1994) Significance of plaque ulceration in symptomatic patients with high grade carotid stenosis: North American Symptomatic Carotid Endarterectomy Trial. Stroke 25:304-308

25. Barnett HJ, Taylor DW, Eliasziw M, Fox AJ, Ferguson GG, Haynes RB et al (1998) Benefit of carotid endarterectomy in patients with symptomatic moderate or severe stenosis. North American Symptomatic carotid Endarterectomy Trial Collaborators. N Engl J Med 339:1415-1425

26. Walker LJ, Ismail Á, McMeekin W, Lambert D, Mendelow AD, Birchall D (2002) Computed tomography angiography for the evaluation of carotid atherosclerotic plaque: correlation with histopathology of endarterectomy specimens. Stroke 33:977-981

27. Randoux B, Marro B, Koskas F (2001) Carotid artery stenosis: prospective comparison of $\mathrm{CT}$, three-dimensional gadoliniumenhanced MR, and conventional angiography. Radiology 220:179-185

28. Saba L, Caddeo G, Sanfilippo R, Montisci R, Mallarini G (2007) Efficacy and sensitivity of axial scans and different reconstruction methods in the study of the ulcerated carotid plaque by using multi-detector-row CT angiography. Comparison with surgical results. AJNR Am J Neuroradiol 28:716-723

29. van Gils MJ, Homburg PJ, Rozie S, de Weert TT, Dippel DW, van der Lugt A (2011) Evolution of atherosclerotic carotid plaque morphology: do ulcerated plaques heal? A serial multidetector CT angiography study. Cerebrovasc Dis 31(3):263-270

30. Cumming MJ, Morrow IA (1994) Carotid artery stenosis: a prospective comparison of CT angiography and conventional angiography. AJR Am J Roentgenol 163:517-523

31. Schwartz RB, Jones KM, Chernoff DM et al (1992) Common carotid artery bifurcation: evaluation with spiral CT. Radiology 185:513-519

32. Etesami M, Hoi Y, Steinman DA, Gujar SK, Nidecker AE, Astor BC, Portanova A, Qiao Y, Abdalla WM, Wasserman BA (2013) Comparison of carotid plaque ulcer detection using contrastenhanced and time-of-flight MRA techniques. AJNR Am J Neuroradiol 34(1):177-184

33. Soloperto G, Casciaro S (2012) Progress in atherosclerotic plaque imaging. World J Radiol 4(8):353-371

34. Underhill HR, Yuan C, Yarnykh VL, Chu B, Oikawa M, Polissar NL, Schwartz SM, Jarvik GP, Hatsukami TS (2009) Arterial remodeling in [corrected] subclinical carotid artery disease. JACC Cardiovasc Imaging 2(12):1381-1389
35. Demarco JK, Ota H, Underhill HR, Zhu DC, Reeves MJ, Potchen MJ, Majid A, Collar A, Talsma JA, Potru S, Oikawa M, Dong L, Zhao X, Yarnykh VL, Yuan C (2010) MR carotid plaque imaging and contrast-enhanced MR angiography identifies lesions associated with recent ipsilateral thromboembolic symptoms: an in vivo study at 3T. AJNR Am J Neuroradiol 31(8):1395-1402

36. Mitsumori LM, Hatsukami TS, Ferguson MS, Kerwin WS, Cai J, Yuan C (2003) In vivo accuracy of multisequence MR imaging for identifying unstable fibrous caps in advanced human carotid plaques. J Magn Reson Imaging 17(4):410-420

37. Hatsukami TS, Ross R, Polissar NL, Yuan C (2000) Visualization of fibrous cap thickness and rupture in human atherosclerotic carotid plaque in vivo with high-resolution magnetic resonance imaging. Circulation 102(9):959-964

38. Saba L, Mallarini G (2009) Fissured fibrous cap of vulnerable carotid plaques and symptomaticity: are they correlated? Preliminary results by using multi-detector-row CT angiography. Cerebrovasc Dis 27(4):322-327

39. Takaya N, Yuan C, Chu B, Saam T, Polissar NL, Jarvik GP, Isaac C, McDonough J, Natiello C, Small R, Ferguson MS, Hatsukami TS (2005) Presence of intraplaque hemorrhage stimulates progression of carotid atherosclerotic plaques: a highresolution magnetic resonance imaging study. Circulation 111(21):2768-2775

40. Altaf N, Daniels L, Morgan PS, Auer D, MacSweeney ST, Moody AR, Gladman JR (2008) Detection of intraplaque hemorrhage by magnetic resonance imaging in symptomatic patients with mild to moderate carotid stenosis predicts recurrent neurological events. J Vasc Surg 47(2):337-342

41. Gao P, Chen ZQ, Bao YH, Jiao LQ, Ling F (2007) Correlation between carotid intraplaque hemorrhage and clinical symptoms: systematic review of observational studies. Stroke 38(8):2382-2390

42. Takaya N, Yuan C, Chu B, Saam T, Underhill H, Cai J, Tran N, Polissar NL, Isaac C, Ferguson MS, Garden GA, Cramer SC, Maravilla KR, Hashimoto B, Hatsukami TS (2006) Association between carotid plaque characteristics and subsequent ischemic cerebrovascular events: a prospective assessment with MRIinitial results. Stroke 37(3):818-823

43. Altaf N, MacSweeney ST, Gladman J, Auer DP (2007) Carotid intraplaque hemorrhage predicts recurrent symptoms in patients with high-grade carotid stenosis. Stroke 38(5):1633-1635

44. Hashimoto N, Hama S, Yamane K, Kurisu K (2012) Carotid arterial intraplaque hemorrhage and calcification influences cerebral hemodynamics. Neurosurg Rev 36(3):421-427

45. Moreno PR, Purushothaman KR, Sirol M, Levy AP, Fuster V (2006) Neovascularization in human atherosclerosis. Circulation 113(18):2245-2252

46. Milei J, Parodi JC, Alonso GF, Barone A, Grana D, Matturri L (1998) Carotid rupture and intraplaque hemorrhage: immunophenotype and role of cells involved. Am Heart $J$ 136(6): 1096-1105

47. Teng Z, He J, Degnan AJ, Chen S, Sadat U, Bahaei NS, Rudd JH, Gillard JH (2012) Critical mechanical conditions around neovessels in carotid atherosclerotic plaque may promote intraplaque hemorrhage. Atherosclerosis 223(2):321-326

48. Cappendijk VC, Cleutjens KB, Kessels AG, Heeneman S, Schurink GW, Welten RJ, Mess WH, Daemen MJ, van Engelshoven JM, Kooi ME (2005) Assessment of human atherosclerotic carotid plaque components with multisequence MR imaging: initial experience. Radiology 234(2):487-492

49. Cappendijk VC, Cleutjens KB, Heeneman S, Schurink GW, Welten RJ, Kessels AG, van Suylen RJ, Daemen MJ, van Engelshoven JM, Kooi ME (2004) In vivo detection of hemorrhage in human atherosclerotic plaques with magnetic resonance imaging. J Magn Reson Imaging 20(1):105-110 
50. Chu B, Kampschulte A, Ferguson MS, Kerwin WS, Yarnykh VL, O'Brien KD, Polissar NL, Hatsukami TS, Yuan C (2004) Hemorrhage in the atherosclerotic carotid plaque: a high-resolution MRI study. Stroke 35(5):1079-1084

51. Ajduk M, Pavić L, Bulimbasić S, Sarlija M, Pavić P, Patrlj L, Brkljacić B (2009) Multidetector-row computed tomography in evaluation of atherosclerotic carotid plaques complicated with intraplaque hemorrhage. Ann Vasc Surg 23(2):186-193

52. Wintermark M, Jawadi SS, Rapp JH, Tihan T, Tong E, Glidden DV, Abedin S, Schaeffer S, Acevedo-Bolton G, Boudignon B, Orwoll B, Pan X, Saloner D (2008) High-resolution CT imaging of carotid artery atherosclerotic plaques. AJNR Am J Neuroradiol 29(5):875-882

53. de Weert TT, Ouhlous M, Meijering E, Zondervan PE, Hendriks JM, van Sambeek MR, Dippel DW, van der Lugt A (2006) In vivo characterization and quantification of atherosclerotic carotid plaque components with multidetector computed tomography and histopathological correlation. Arterioscler Thromb Vasc Biol 26(10):2366-2372

54. Ajduk M, Pavić L, Bulimbasić S, Sarlija M, Pavić P, Patrlj L, Brkljacić B (2000) Multidetector-row computed tomography in evaluation of atherosclerotic carotid plaques complicated with intraplaque hemorrhage. Ann Vasc Surg 23:186-193

55. Saba L, Montisci R, Sanfilippo R, Mallarini G (2009) Multidetector row $\mathrm{CT}$ of the brain and carotid artery: a correlative analysis. Clin Radiol 64(8):767-778

56. Nandalur KR, Baskurt E, Hagspiel KD, Phillips CD, Kramer CM (2005) Calcified carotid atherosclerosic plaque is associated less with ischemic symptoms than is noncalcified plaque on MDCT. AJR Am J Roentgenol 184:295-298

57. Kondos GT, Hoff JA, Sevrukov A (2003) Electronbeam tomography coronary artery calcium and cardiac events: a 37-month follow-up of 5635 initially asymptomatic low- to intermediate-risk adults. Circulation 107:2571-2576

58. Sangiorgi G, Rumberger JA, Severson A (1998) Arterial calcification and not lumen stenosis is highly correlated with atherosclerotic plaque burden in humans: a histologic study of 723 coronary artery segments using nondecalcifying methodology. J Am Coll Cardiol 31:126-133

59. Saba L, Mallarin G (2009) Window settings for the study of calcified carotid plaques with multidetector CT angiography. AJNR Am J Neuroradiol 30(7):1445-1450

60. Geroulakos G, Ramaswani G, Nicolaides A (1993) Characterization of symptomatic and asymptomatic carotid plaques using high resolution real time ultrasound. $\mathrm{Br} \mathrm{J}$ Surg 180:1274-1277

61. Saba L, Sanfilippo R, Montisci R, Atzeni M, Ribuffo D, Mallarini G (2011) Vulnerable plaque: detection of agreement between multi-detector-row CT angiography and US-ECD. Eur J Radiol 77(3):509-515

62. Tahmasebpour HR, Buckley AR, Cooperberg PL, Fix $\mathrm{CH}$ (2005) Sonographic examination of the carotid arteries. RadioGraphics 25:1561-1575

63. Saba L, Montisci R, Raz E, Sanfilippo R, Suri JS, Piga M (2012) Association between carotid artery plaque type and cerebral microbleeds. AJNR Am J Neuroradiol 33(11):2144-2150

64. Saba L, Pascalis L, Sanfilippo R, Anzidei M, Bura R, Montisci R, Mallarini G (2011) Carotid artery wall thickness and leukoaraiosis: preliminary results using multidetector row $\mathrm{CT}$ angiography. AJNR Am J Neuroradiol 32(5):955-961

65. Saba L, Sanfilippo R, Pascalis L, Montisci R, Mallarini G (2009) Carotid artery abnormalities and leukoaraiosis in elderly patients: evaluation with MDCT. AJR Am J Roentgenol 192(2):W63-W70

66. Kamenskiy AV, Pipinos II, Dzenis YA, Bikhchandani J, Gupta PK, Phillips N, Jaffar Kazmi SA, Mactaggart JN (2013) Effects of carotid artery stenting on arterial geometry. J Am Coll Surg. doi:10.1016/j.jamcollsurg.2013.03.016

67. Tsutsumi M, Kodama T, Aikawa H, Onizuka M, Iko M, Nii K, Hamaguchi S, Etou H, Sakamoto K, Inoue R, Nakau H, Kazekawa K (2010) Fragmentation of calcified plaque after carotid artery stenting in heavily calcified circumferential stenosis. Neuroradiology 52(9):831-836

68. Ouhlous M, Flach HZ, de Weert TT (2005) Carotid plaque composition and cerebral infarction: MR imaging study. Am J Neuroradiol 26:1044-1049

69. Ukwatta E, Yuan J, Rajchl M, Qiu W, Tessier D, Fenster A (2013) 3-D carotid multi-region MRI segmentation by globally optimal evolution of coupled surfaces. IEEE Trans Med Imaging 32(4):770-785

70. Saba L, Sanfilippo R, Sannia S, Anzidei M, Montisci R, Mallarini G, Suri JS (2012) Association between carotid artery plaque volume, composition, and ulceration: a retrospective assessment with MDCT. AJR Am J Roentgenol 199:151-156

71. Barger AC, Beeuwkes R 3rd, Lainey LL, Silverman KJ (1984) Hypothesis: vasa vasorum and neovascularization of human coronary arteries: a possible role in the pathophysiology of atherosclerosis. N Engl J Med 310:175-177

72. Kolodgie FD, Gold HK, Burke AP, Fowler DR, Kruth HS, Weber DK, Farb A, Guerrero LJ, Hayase M, Kutys R, Narula J, Finn AV, Virmani R (2003) Intraplaque hemorrhage and progression of coronary atheroma. N Engl J Med 349:2316-2325

73. Zhou Y, Xing Y, Li Y, Bai Y, Chen Y, Sun X, Zhu Y, Wu J (2013) An assessment of the vulnerability of carotid plaques: a comparative study between intraplaque neovascularization and plaque echogenicity. BMC Med Imaging 28(13):13. doi:10. 1186/1471-2342-13-13

74. Kunte H, Schmidt C, Harms L, Rückert RI, Grigoryev M, Fischer T (2012) Contrast-enhanced ultrasound and detection of carotid plaque neovascularization. Neurology 79(20):2081

75. Ten Kate GL, van den Oord SC, Sijbrands EJ, van der Lugt A, de Jong N, Bosch JG, van der Steen AF, Schinkel AF (2013) Current status and future developments of contrast-enhanced ultrasound of carotid atherosclerosis. J Vasc Surg 57(2):539-546

76. Jaipersad AS, Shantsila A, Silverman S, Lip GY, Shantsila E (2012) Evaluation of carotid plaque neovascularization using contrast ultrasound. Angiology. doi:10.1177/00033197124 57013

77. Saba L, Lai ML, Montisci R, Tamponi E, Sanfilippo R, Faa G, Piga M (2012) Association between carotid plaque enhancement shown by multidetector CT angiography and histologically validated microvessel density. Eur Radiol 22(10):2237-2245. doi:10.1007/s00330-012-2467-5

78. Horie N, Morikawa M, Ishizaka S, Takeshita T, So G, Hayashi K, Suyama K, Nagata I (2012) Assessment of carotid plaque stability based on the dynamic enhancement pattern in plaque components with multidetector CT angiography. Stroke 43(2):393-398

79. Saba L, Piga M, Raz E, Farina D, Montisci R (2012) Carotid artery plaque classification: does contrast enhancement play a significant role? AJNR Am J Neuroradiol 33(9):1814-1817. doi:10.3174/ajnr.A3073

80. Saba L, Mallarini G (2011) Carotid plaque enhancement and symptom correlations: an evaluation by using multidetector row CT angiography. AJNR Am J Neuroradiol 32(10):1919-1925. doi:10.3174/ajnr.A2605

81. Romero JM, Babiarz LS, Forero NP, Murphy EK, Schaefer PW, Gonzalez RG, Lev MH (2009) Arterial wall enhancement overlying carotid plaque on CT angiography correlates with symptoms in patients with high grade stenosis. Stroke 40(5): 1894-1896 
82. Qiao Y, Etesami M, Astor BC, Zeiler SR, Trout HH 3rd, Wasserman BA (2012) Carotid plaque neovascularization and hemorrhage detected by MR imaging are associated with recent cerebrovascular ischemic events. AJNR Am J Neuroradiol 33(4):755-760

83. Lobbes MB, Heeneman S, Passos VL, Welten R, Kwee RM, van der Geest RJ, Wiethoff AJ, Caravan P, Misselwitz B, Daemen MJ, van Engelshoven JM, Leiner T, Kooi ME (2010) Gadofosveset-enhanced magnetic resonance imaging of human carotid atherosclerotic plaques: a proof-of-concept study. Invest Radiol 45(5):275-281

84. Oppenheim C, Naggara O, Touzé E, Lacour JC, Schmitt E, Bonneville F, Crozier S, Guégan-Massardier E, Gerardin E, Leclerc X, Neau JP, Sirol M, Toussaint JF, Mas JL, Méder JF (2009) Highresolution MR imaging of the cervical arterial wall: what the radiologist needs to know. Radiographics 29(5):1413-1431

85. Gaens ME, Backes WH, Rozel S, Lipperts M, Sanders SN, Jaspers K, Cleutjens JP, Sluimer JC, Heeneman S, Daemen MJ, Welten RJ, Daemen JW, Wildberger JE, Kwee RM, Kooi ME (2013) Dynamic contrast-enhanced MR imaging of carotid atherosclerotic plaque: model selection, reproducibility, and validation. Radiology 266(1):271-279

86. Shah F, Balan P, Weinberg M, Reddy V, Neems R, Feinstein M, Dainauskas J, Meyer P, Goldin M, Feinstein SB (2007) Contrast-enhanced ultrasound imaging of atherosclerotic carotid plaque neovascularization: a new surrogate marker of atherosclerosis? Vasc Med 12(4):291-297

87. Feinstein SB (2006) Contrast ultrasound imaging of the carotid artery vasa vasorum and atherosclerotic plaque neovascularization. J Am Coll Cardiol 48(2):236-243

88. Vicenzini E, Giannoni MF, Puccinelli F, Ricciardi MC, Altieri M, Di Piero V, Gossetti B, Valentini FB, Lenzi GL (2007) Detection of carotid adventitial vasa vasorum and plaque vascularization with ultrasound cadence contrast pulse sequencing technique and echo-contrast agent. Stroke 38(10):2841-2843

89. Staub D, Partovi S, Schinkel AF, Coll B, Uthoff H, Aschwanden M, Jaeger KA, Feinstein SB (2011) Correlation of carotid artery atherosclerotic lesion echogenicity and severity at standard US with intraplaque neovascularization detected at contrastenhanced US. Radiology 258(2):618-626

90. Chappell FM, Wardlaw JM, Young GR et al (2009) Carotid artery stenosis: accuracy of noninvasive tests-individual patient data meta-analysis. Radiology 251:493-502

91. Kawahara I, Morikawa M, Honda M, Kitagawa N, Tsutsumi K, Nagata I, Hayashi T, Koji T (2007) High-resolution magnetic resonance imaging using gadolinium-based contrast agent for atherosclerotic carotid plaque. Surg Neurol 68(1):60-65 discussion 65-66

92. Yuan C, Kerwin WS, Ferguson MS, Polissar N, Zhang S, Cai J, Hatsukami TS (2002) Contrast-enhanced high-resolution MRI for atherosclerotic carotid artery tissue characterization. J Magn Reson Imaging 15(1):62-67

93. Kerwin W, Hooker A, Spilker M, Vicini P, Ferguson M, Hatsukami T, Yuan C (2003) Quantitative magnetic resonance imaging analysis of neovasculature volume in carotid atherosclerotic plaque. Circulation 107(6):851-856

94. Kerwin WS, O'Brien KD, Ferguson MS, Polissar N, Hatsukami TS, Yuan C (2006) Inflammation in carotid atherosclerotic plaque: a dynamic contrast-enhanced MR imaging study. Radiology 241(2):459-468

95. Papini GD, Di Leo G, Tritella S, Nano G, Cotticelli B, Clemente C, Tealdi DG, Sardanelli F (2011) Evaluation of inflammatory status of atherosclerotic carotid plaque before thromboendarterectomy using delayed contrast-enhanced subtracted images after magnetic resonance angiography. Eur J Radiol 80(3):e373-e380

96. Millon A, Boussel L, Brevet M, Mathevet JL, Canet-Soulas E, Mory C, Scoazec JY, Douek P (2012) Clinical and histological significance of gadolinium enhancement in carotid atherosclerotic plaque. Stroke 43(11):3023-3028

97. Anzidei M, Napoli A, Marincola BC, Kirchin MA, Neira C, Geiger D, Zaccagna F, Catalano C, Passariello R (2009) Highresolution steady state magnetic resonance angiography of the carotid arteries: are intravascular agents necessary? Feasibility and preliminary experience with gadobenate dimeglumine. Invest Radiol 44(12):784-792

98. Anzidei M, Napoli A, Marincola BC, Nofroni I, Geiger D, Zaccagna F, Catalano C, Passariello R (2009) Gadofosvesetenhanced MR angiography of carotid arteries: does steady-state imaging improve accuracy of first-pass imaging? Comparison with selective digital subtraction angiography. Radiology 251(2):457-466

99. Ruehm SG, Corot C, Vogt P, Cristina H, Debatin JF (2002) Ultrasmall superparamagnetic iron oxide-enhanced MR imaging of atherosclerotic plaque in hyperlipidemic rabbits. Acad Radiol 9(Suppl 1):S143-S144

100. Trivedi RA, Mallawarachi C, U-King-Im JM, Graves MJ, Horsley J, Goddard MJ, Brown A, Wang L, Kirkpatrick PJ, Brown J, Gillard JH (2006) Identifying inflamed carotid plaques using in vivo USPIO-enhanced MR imaging to label plaque macrophages. Arterioscler Thromb Vasc Biol 26(7):1601-1606

101. Koelemay MJ, Nederkoorn PJ, Reitsma JB, Majoie CB (2004) Systematic review of computed tomographic angiography for assessment of carotid artery disease. Stroke 35(10):2306-2312

102. Hardie AD, Kramer CM, Raghavan P, Baskurt E, Nandalur KR (2007) The impact of expansive arterial remodeling on clinical presentation in carotid artery disease: a multidetector CT angiography study. AJNR Am J Neuroradiol 28(6):1067-1070

103. Paul J, Mbalisike EC, Nour-Eldin NE, Vogl TJ (2013) Dualsource 128-slice MDCT neck: radiation dose and image quality estimation of three different protocols. Eur J Radiol 82(5):787-796

104. Fleischmann D, Boas FE (2011) Computed tomography-old ideas and new technology. Eur Radiol 21:510-517

105. Mannelli L, Mitsumori LM, Ferguson M, Xu D, Chu B, Branch KR, Shuman WP, Yuan C (2013) Changes in measured size of atherosclerotic plaque calcifications in dual-energy $\mathrm{CT}$ of ex vivo carotid endarterectomy specimens: effect of monochromatic $\mathrm{keV}$ image reconstructions. Eur Radiol 23(2):367-374

106. Saba L, Argiolas GM, Siotto P, Piga M (2013) Carotid artery plaque characterization using CT multienergy imaging. AJNR Am J Neuroradiol 34(4):855-859

107. Goessens BM, Visseren FL, Kappelle LJ, Algra A, van der GY (2007) Asymptomatic carotid artery stenosis and the risk of new vascular events in patients with manifest arterial disease: the SMART study. Stroke 38:1470-1475

108. Marquardt L, Geraghty OC, Mehta Z, Rothwell PM (2010) Low risk of ipsilateral stroke in patients with asymptomatic carotid stenosis on best medical treatment: a prospective, populationbased study. Stroke 41:e11-e17

109. Nicolaides AN, Kakkos SK, Griffin M, Sabetai M, Dhanjil S, Tegos $\mathrm{T}$ et al (2005) Severity of asymptomatic carotid stenosis and risk of ipsilateral hemispheric ischaemic events: results from the ACSRS study. Eur J Vasc Endovasc Surg 30:275-284

110. Brott TG, Hobson RW, Howard G, Roubin GS, Clark WM, Brooks W et al (2010) Stenting versus endarterectomy for treatment of carotid-artery stenosis. N Engl J Med 363:11-23

111. Vanninen R, Manninen H, Soimakallio S (1995) Imaging of carotid artery stenosis: clinical efficacy and cost-effectiveness. AJNR Am J Neuroradiol 16(9):1875-1883

112. Wardlaw JM, Chappell FM, Stevenson M, De Nigris E, Thomas S, Gillard J, Berry E, Young G, Rothwell P, Roditi G, Gough M, Brennan A, Bamford J, Best J (2006) Accurate, practical and cost-effective assessment of carotid stenosis in the UK. Health Technol Assess 10(30):iii-iv, ix-x, 1-182 